\title{
Psychopathology and movement disorders: a new perspective on the Gilles de la Tourette syndrome
}

\author{
MICHAEL TRIMBLE \\ From the Department of Clinical Neurology, Institute of Neurology, the National Hospital for Nervous Diseases, \\ London, UK
}

SUMMARY Attention is drawn to associations between movement disorders and psychopathology. The historical background of this is briefly reviewed, and then some recent research findings with regards to the Gilles de la Tourette syndrome are presented. In particular, associations between aggressive and obsessive compulsive disorder and Gilles de la Tourette movements are reported. Further there are associations between a family history of tics and obsessive compulsive disorder in the subsequent generation. It is concluded that the Gilles de la Tourette syndrome should not be viewed as a tic disorder, but a far more complex condition in which the tics form but one aspect.

The relationship between movement disorders and psychopathology is of growing interest from several points of view. First, abnormal movements are noted in a number of patients following drug therapy for psychotic illnesses. Many distinct syndromes have been described, but often their presentations can remain unrecognised, misdiagnosed as hysteria, or mistaken for worsening of the underlying psychiatric illness. Secondly, there are a number of primary movement disorders in which psychopathology occurs during the course of the illness, or on occasions prior to the onset of the abnormal movements. Huntington's chorea would be an example. Finally, recent developments in neuroanatomy and neurochemistry have highlighted important relationships between neuronal systems which modulate both movement and emotion, suggesting biological underpinnings for clinical observations which have been made over the years.

There have been several reviews of this topic ${ }^{12}$ including a recent assay from Professor Marsden ${ }^{3}$ in which he concluded "movement is one of the robust bridges between neurology and psychiatry, built upon solid foundations that tantalise those in both disciplines".

It is the purpose of this paper to review briefly some research which has been carried out at the Institute of Neurology, Queen Square, on the Gilles de la Tourette

Address for reprint requests: Dr M Trimble, Institute of Neurology, National Hospital for Nervous Diseases, Queen Square, London WCIN 3BG, UK.

Accepted January 1989 syndrome which highlights specific aspects of the in psychopathology of the syndrome. This has not only led to new directions for research, but also challenges some of the currently held conceptions about the condition.

\section{Gilles de la Tourette syndrome}

Gilles de la Tourette described the syndrome that bears his name in $1885 .^{4}$ Following a flurry of case reports which followed shortly thereafter, the condi tion virtually disappeared from the literature until the 1960s when a resurgence of interest occurred following the reported success of Haloperidol in its treatment. Since then the Gilles de la Tourette syndrome has been subject to several reviews ${ }^{56}$ and, far from being the rare disorder it was once thought, is now being reported in increasing numbers, especially the less severe variants.

The most recent diagnostic criteria, as given in DSM III $R$ are shown in table 1 . It is clear that the essential feature of the disorder is the tic, and indeed the condition is invariably classified as a tic disorder. ${ }^{7}$ It is here suggested, however, that to refer to the syndrome of Gilles de la Tourette simply as a tic disorder is to ignore many of the richer manifestations of the condition, and to be unfamiliar with its pleomorphic clinical presentations.

There can be no better starting point for discussing the psychopathology of tics than to read Meige and Feindel's Tics and their Treatment published in $1907 .^{8}$ The Confessions of a Victim to Tic describes the symptoms of a 54 year old man who would now be diagnosed as having the Gilles de la Tourette syndrome. He suffered from a wide variety of tics, 
Table 1 The diagnostic criteria for Gilles de la Tourette syndrome (DSM III R $)^{7}$

A) Both multiple motor and one or more vocal tics have been present at some time during the illness, although not necessarily concurrently.

B) The tics occur many times a day (usually in bouts), nearly every day or intermittently throughout a period of more than one year.

C) The anatomical location, number, frequency and severity of the tics change over time.

D) Onset before the age of 21 years.

E) Occurrence not exclusively during psychoactive substance intoxication or known central nervous system disease, such as Huntington's chorea and post viral encephalitis.

echolalia and echopraxia, complicated movements, and "a tic of phonation". The authors drew attention to the "fundamental importance of the psychical element that precedes the motor reaction", and documented the patient's impulsivity, suicidal tendencies and obsessive compulsive behaviour. They noted his obsessional fears and suggested intimate analogies between tics and obsessions. They concluded "it has been possible to determine the origin of the tics and to confirm the association with them of a peculiar mental state". Meige and Feindel noted that Trousseau, in 1873 , had drawn attention to the fact that the mental state of patients with tics was abnormal, but gave credit to Charcot for demonstrating the significance of psychical factors.

Interestingly, in Gilles de la Tourette's original description, little mention was made of associated psychopathology with the exception of excessive fear. In his 1899 paper $^{9}$ he developed the theme further. Acknowledging the hereditary factor, he commented on the anxieties and phobias of his patients. Further, he acknowledged the contributions of Guinon who had reported that "tiqueurs" nearly always had associated psychiatric problems characterised by multiple phobias, arithmomania and agoraphobia. Gilles de la Tourette made the point that the mental stigmata appeared late in the natural history of the condition, but that it was rare for an adult case to be completely free from them. Further they were more pronounced during the period of exacerbation of the tics.

Subsequently, writers have developed three common themes on the relationship between Gilles de la Tourette syndrome and psychopathology. The first relates to the development of a paranoid state or psychosis, the second to aggression, and the third to obsessive compulsive features.

The potential for patients with the syndrome to develop psychosis was inherent in the 19th century view of degeneration. Gilles de la Tourette concurred with this theory and there have been anecdotal reports of patients who appear to develop psychosis in the course of their illness. However, none of the extensive series of follow ups which have been carried out in recent years support any obvious association, and the development of a psychotic state in the condition is rare.

The theme of aggression was of particular interest to writers of psychoanalytic persuasion suggesting that the tic represented some form of internalised, unexpressed aggression, or was seen as a defence against aggressive impulses or as an outlet for unmanageable aggressive feelings. This theme, and the relationship to obsessive compulsive disorder, have been the subject of several studies carried out at the Institute of Neurology, the results of which will be briefly summarised.

\section{The psychopathology of Gilles de la Tourette syndrome: a phenomenological analysis}

There has been a referral clinic at the National Hospital, Queen Square, for patients with the Gilles de la Tourette syndrome for a number of years, and systematic detailed information has been kept on all patients attending. The neurological findings from the first 53 patients have been fully described ${ }^{10}$ in which we highlighted the similarity of our population with other reported series. We noted the relative low frequency of abnormal neurological signs, only $13 \%$ showing an abnormal electro-encephalogram, and nearly all having a normal CT scan. We have further highlighted the interesting finding ${ }^{11}$ that $12.5 \%$ of patients show low copper levels, which in some cases is related to abnormalities of copper handing, although these patients are not identified by any particular neurological features.

The psychopathology of the first 90 patients who fulfilled the DSM III criteria for Gilles de la Tourette syndrome was assessed using clinical evaluation procedures, and the following rating scales were completed: the Beck depression inventory; the Spielberger trait anxiety inventory; the borderline syndrome index; the mood adjective check list; the Middlesex Hospital questionnaire; the Eysenck personality inventory; the hostility and direction of hostility questionnaire; and the questionnaire of the Leyton obsessional inventory.

In this investigation, no patients were found who were psychotic, although three exhibited ideas of reference. Fifteen were judged clinically to have depressive symptoms severe enough to constitute a major affective disorder, and 25 had severe anxiety. Seventy six patients had disorders of sleep including night terrors, insomnia, sleep talking, sleep walking, nightmares and nocturnal enuresis. These data with regard to general psychopathology, are not dissimilar to those of other series, for example that of Shapiro $e t$ $a l .{ }^{5}$ The latter concluded "most Tourette patients had some degree of maladjustment. Their problems were 
Table 2 Relationship between certain symptoms of the Gilles de la Tourette syndrome and aggression

\begin{tabular}{|c|c|c|c|c|c|}
\hline \multirow[b]{2}{*}{ Symptoms or demographic details } & \multirow[b]{2}{*}{ Aggressive behaviour } & \multicolumn{4}{|c|}{ Hostility and direction of hostility questionnaire } \\
\hline & & Criticism of others & Paranoid hostility & Self criticism & Sum of hostility \\
\hline $\begin{array}{l}\text { Forced to touch } \\
\text { Coprophenomena } \\
\text { Echophenomena }\end{array}$ & $\stackrel{*}{\dagger(\text { Copropraxia })}$ & $\dagger($ Coprolalia $)$ & ${ }_{*}^{*}$ (Coprolalia) & $\dagger$ & ${ }_{\dagger}^{*}$ (Coprolalia) \\
\hline
\end{tabular}

$*<0.05 ; \nmid<0.01$.

Table 3 Examples of self-injurious behaviour in patients with Gilles de la Tourette syndrome

\begin{tabular}{lc}
\hline Behaviour & No of cases \\
\hline Head banging & 14 \\
Body punching & 10 \\
Head or face punching & 9 \\
Body to hard object banging & 8 \\
Poking sharp objects into body & 2 \\
Scratching parts of body & 2 \\
Putting hands through window & 2 \\
Other single types of self-injurious behaviour & 12 \\
\hline
\end{tabular}

no more severe, however, than those of a psychiatric out patient group".

Aggressive and self destructive behaviour The association between aggressive behaviours and some of the symptoms of Gilles de la Tourette syndrome are shown in table 2.

Twenty eight patients had been physically aggressive to other people, animals or property. The aggressive behaviour was significantly associated with the symptoms of being forced to touch and copropraxia. Patients scored highly on the hostility questionnaire, and extra-punitive items, such as acting out hostility and criticism of others, were unrelated to depression scores. The kinds of self injurious behaviours recorded are shown in table 3. Thirteen out of fourteen head bangers had CT scans carried out and two had cavum septum pellucida.

Self injurious behaviour was related to the cumulative sum of motor tics ever and tics of the legs, while subjects with head banging reported a greater number of cumulative motor tics than those without. We have noted a particular association between the syndrome and self damage to the eyes. ${ }^{12}$ Thus self injurious behaviour is reported in several populations of patients including the mentally retarded, those with personality disorder and those with psychosis. Interestingly, the pattern of damage differs between these groups, wrist cutting, for example, being common in personality disorders, while ocular damage occurs more frequently in psychotic patients. As we have noted, our patients do not present with psychotic features but we have seen several patients who have severely damaged their eyes. We have recently reported a case whose eyes were so frequently traumatised that blindness was an inevitable outcome. Neurosurgical intervention with an anterior cingulectomy for this behaviour was considered necessary and dramatically improved his behaviour. ${ }^{13}$

We have also carried out a comparative study of aggressive behaviour in patients with spasmodic torticollis, writer's cramp and the Gilles de la Tourette syndrome. ${ }^{14}$ Sixteen patients with spasmodic torticollis, eight with writer's cramp, and 20 with the Gilles de la Tourette syndrome were compared with 25 normal controls, each clinical group having its own age and sex match controls. They were administered the hostility and direction of hostility questionnaire of Foulds. The results from this study are shown in table 4.

The extrapunitive scores of acting out hostility and criticism of others and the sum of hostility scores showed significant differences between the groups, patients with writer's cramp scoring significantly higher than controls. On criticism of others they were significantly higher than patients with spasmodic torticollis. The latter patients showed no significant

Table 4 Scores on a hostility rating scale in three abnormal movement disorders and controls

\begin{tabular}{|c|c|c|c|c|c|c|}
\hline \multirow[b]{2}{*}{ Group } & \multicolumn{2}{|c|}{ Acting out hostility } & \multicolumn{2}{|c|}{ Criticism of others } & \multicolumn{2}{|c|}{ Sum of hostility } \\
\hline & Median & Range & Median & Range & Median & Range \\
\hline $\begin{array}{l}\text { Spasmodic torticollis } \\
\text { Writer's cramp } \\
\text { Gilles de la Tourette } \\
\text { Controls }\end{array}$ & $\begin{array}{l}4 \cdot 0 \\
5 \cdot 0^{*} \\
5 \cdot 5^{*} \\
3 \cdot 0 \ddagger\end{array}$ & $\begin{array}{l}1-10 \\
2-6 \\
2-10 \\
2-8\end{array}$ & $\begin{array}{l}3 \cdot 0^{*} \\
7 \cdot 0 \\
5 \cdot 0 \\
4 \cdot 0\end{array}$ & $\begin{array}{l}0-8 \\
3-7 \\
0-11 \\
0-8\end{array}$ & $\begin{array}{l}15 \cdot 0 \\
20 \cdot 0^{*} \\
22 \cdot 5^{*} \\
13 \cdot 0\end{array}$ & $\begin{array}{l}4-32 \\
8-25 \\
5-33 \\
5-27 \ddagger\end{array}$ \\
\hline
\end{tabular}

*< $0.05 ; \ddagger<0.01$. 
differences from controls while patients with the Gilles de la Tourette syndrome scored higher on acting out hostility than controls but were no different from patients with the other two movement disorders on their scores of acting out hostility or criticism of others. When the sum of hostility scores were analysed, Gilles de la Tourette patients scored significantly higher than the other three groups.

These data suggest that aggressive behaviour and self mutilation are not uncommonly reported in patients with the Gilles de la Tourette syndrome, and the types of behaviours noted may have forensic relevance. and further be amenable to and need specific treatment. The comparison between the movement disorders suggests that differences with regard to this aspect of behaviour may exist, patients with Gilles de la Tourette syndrome being significantly different from those with writer's cramp and spasmodic torticollis. We have further identified differences with regard to hostility between writer's cramp and spasmodic torticollis. This is particularly interesting with regard to writer's cramp, as others have noted difficulty in expressing anger and hostility in this condition $^{14}$ and significantly higher forearm tension has been noted during electromyographic investigations of subjects with writer's cramp when discussing topics concerning anger and hostility. ${ }^{15}$ The fact that we find significant associations between scaled assessments of aggressive behaviour and some of the key motor symptoms of the Gilles de la Tourette syndrome suggest that this link may reflect underlying biological associations between the two phenomena.

Obsessive compulsive disorder In the National Hospital study, 33 patients admitted to obsessive compulsive behaviour and/or rituals. This was associated with significantly higher scores on the obsessional rating scales, but no relationship was found between obsessive compulsive disorder scores and depression scores. The associations between obsessive compulsive behaviour and the motor symp- toms of the Gilles de la Tourette syndrome are shown in table 5.

Obsessive compulsive behaviour was significantly associated with the symptom of feeling forced to touch and shoulder shrugging. The clinical diagnosis of obsessive compulsive behaviour was significantly associated with high scoring on both the Middlesex Hospital questionnaire obsessional scale and the Leyton obsessional inventory. Specifically, coprolalia was significantly related to the Leyton obsessional inventory symptom and total scores, while echo phenomena were significantly related to high Middlesex Hospital obsessional scores and the Leyton obsessional index trait scores.

Echo phenomena were further associated in this study with the severity of the Gilles de la Tourette syndrome as measured by the total number and cumulative number of motor tics ever. It should be noted that our clinical diagnosis of obsessive compulsive disorder was based on clinical features and specifically did not include urges to tic, vocalise or to touch. Typical examples of obsessive compulsive behaviour were checking rituals, smelling of objects, avoiding certain eating utensils, repetitive rituals, folding rituals, walking on squares or lines on the pavement, walking in the middle of a busy road to prevent anything bad or untoward happening, excessive hand washing, arithmomania and obsessions of doing harm to close relatives.

In view of the high frequency of obsessive compulsive behaviour reported in the study, a cross cultural comparison has been carried out in conjunction with a group from Los Angeles. ${ }^{16}$ A questionnaire was constructed specifically to elicit obsessive compulsive behaviour which was given to five groups of patients. These were 31 Gilles de la Tourette patients from the United States, and 33 from Great Britain; twelve patients met DSM III criteria for obsessive compulsive disorder and had no tics, and two control groups were used, one consisting of patients with differing neuro-

Table 5 Relationship between certain symptoms of the Gilles de la Tourette syndrome and obsessional behaviour

\begin{tabular}{|c|c|c|c|c|c|}
\hline \multirow{3}{*}{$\begin{array}{l}\text { Symptoms or } \\
\text { demographic details }\end{array}$} & \multicolumn{5}{|c|}{ Obsessive compulsive phenomena } \\
\hline & \multirow{2}{*}{$\begin{array}{l}\text { Obsessive } \\
\text { compulsive } \\
\text { behaviour }\end{array}$} & \multicolumn{3}{|c|}{ Leyton Obsessional Inventory } & \multirow{2}{*}{$\begin{array}{l}\text { MHQ } \\
\text { Obsessional } \\
\text { Scale }\end{array}$} \\
\hline & & Symptom & Trait & Total & \\
\hline \multirow{2}{*}{$\begin{array}{l}\text { Forced to touch } \\
\text { Coprophenomena } \\
\text { Echophenomena } \\
\text { Family history }\end{array}$} & $\ddagger$ & *(Coprolalia) & $*$ & *(Coprolalia) & $\delta$ \\
\hline & $\begin{array}{l}\text { * Family history of } \\
\text { TS or tics }\end{array}$ & $\begin{array}{l}\text { *With family history } \\
\text { of psychiatric } \\
\text { illness }\end{array}$ & & $\begin{array}{l}\text { *With family history } \\
\text { of TS or tics }\end{array}$ & $\mathbf{y}$ \\
\hline $\begin{array}{l}\text { Tic } \\
\text { Medication }\end{array}$ & †Shoulder shrug & $\begin{array}{l}\ddagger \text { With } \\
\text { butyrophenones }\end{array}$ & $\begin{array}{l}\mp \text { With } \\
\text { butyrophenones }\end{array}$ & $\begin{array}{l}\mp \text { With } \\
\text { butyrophenones }\end{array}$ & \\
\hline
\end{tabular}

$*<0.05 ; \dagger<0.01 ; \ddagger<0.005 ; \S<0.001$. 
psychiatric disorders and the other of 41 normals. Obsessive compulsive disorder patients had the highest mean score on this scale. Using the same criteria, $58 \%$ and $45 \%$ of the USA and British patients with the Gilles de la Tourette syndrome respectively scored in the same range as those with obsessive compulsive disorders in comparison with $12 \%$ and $18 \%$ in the two control groups. This study therefore confirmed the frequency of obsessive compulsive disorder in the condition, and its presence in different cultural settings.

Thus obsessive compulsive disorder is a feature of the Gilles de la Tourette syndrome, and we have highlighted intimate links between motor symptoms, severity of the disorder and these obsessive compulsive phenomena. This has implications for treatment, since in our experience the obsessive compulsive phenomena can be considerably more disabling to patients than their tics. Psychopharmacological treatments are available including drugs with selective 5HT uptake inhibitor properties, but alternative treatments include behaviour therapy for the majority and, in severe cases, psychosurgery.

Confirmation of the close association between obsessive compulsive symptoms and motor symptoms has led to a conceptual shift with regard to an understanding of the syndrome. Data from recent family studies ${ }^{17}$ suggest that the Gilles de la Tourette syndrome and obsessive compulsive phenomena are aetiologically related with a common genetic basis. Some authors believe it to be inherited as an autosomal dominant trait, with reduced penetrance and variable expressivity ${ }^{18}$ such that when family 14 members with the Gilles de la Tourette syndrome, or chronic motor tics or obsessive compulsive behaviours are included, the penetrance may approach $100 \%$ in males and $70 \%$ in females. Obsessive compulsive behaviour is thus seen as a major phenotypic form of expression of the Gilles de la Tourette syndrome gene. Interestingly, in the National Hospitals study, further confirmation is found. Thus, obsessive compulsive behaviour, and scoring on the Leyton obsessional inventory by Probands, were associated with a family history of Gilles de la Tourette syndrome or tics.

The other side of this relationship is now being explored. For example, Pitman et al ${ }^{19}$ compared 16 patients with the Gilles de la Tourette syndrome with 16 patients who had obsessive compulsive disorder and 16 normal controls. In addition to the high incidence of obsessive compulsive behaviour in Gilles de la Tourette patients, there was a significantly greater incidence of tics in patients with obsessive compulsive disorder and their relatives. The tics generally preceded the development of the obsessive compulsive behaviour.

\section{Conclusions}

With a little reflection, it seems obvious that movements and emotions are interconnected. Just consider the word emotion itself, composed entirely of the word motion with the prefix "e". Although such associations were discussed by the neuropsychiatrists of the late 19th century, until recently they have been relatively neglected with the exception of a few talented writers over the years, Smith Ely Jelliffe, and Richard Hunter being outstanding examples. ${ }^{20}$ The Gilles de la Tourette syndrome is widely regarded as a tic disorder, but as the data in this paper emphasise, the tics are but one reflection of the pleomorphic phenomenology that these patients display. Even those who have expressed only an interest in the movement aspects of this condition must surely reflect on the wide panoply of movements other than tics displayed by these patients. Not only would this include a number of the compulsive rituals described, but brief discussion with many patients with the condition will reveal their diverse complicated movements which form part of their overall abnormal movement spectrum. The gait disorders, genuflexions, stereotopes, habits and mannerisms, must all be considered along with the symptoms described here as part of the complex behavioural repertoire of patients with the syndrome. Bliss ${ }^{20}$ a life long sufferer from the Gilles de la Tourette syndrome, described his self observation of his symptoms and comments thus "the TS movement is not the whole message. The TS movement is not rhythmic, spasmodic or involuntary. The movement only seems involuntary because of the instant capitulation to the unrecognised sensory stimulus. It can be detected and interrupted when in progress and at any stage". Bliss rails over clinical evaluations which concentrate only on tics, noting that "the movement, even if grotesque and miserable, is not the most important part of TS activity".

\section{References}

1 Trimble MR. Neuropsychiatry. Chichester: J Wiley and Sons, 1981.

2 Lishman A. Organic Psychiatry 2nd ed. Oxford: Blackwells, 1988.

3 Marsden CD. Movement Disorders in Neuropsychiatry. In: Reynolds EH, Trimble MR, eds. The Bridge between Neurology and Psychiatry. Edinburgh: Churchill Livingstone, 1989.

4 Gilles de la Tourette G. Etude sur une affection nerveuse caracterisée par de l'incoordination motrice accompagnée d'echolalie et de coprolalie. Archives de Neurologie 1885;9: 19-42, 158-200.

5 Shapiro AK, Shapiro ES, Bruun RD, Sweet RD. Gilles de la Tourette Syndrome. New York: Raven Press, 1978.

6 Cohen D, Bruun R. Gilles de la Tourette Syndrome and Tic Disorders. New York: J Wiley and Sons, 1988.

7 American Psychiatric Association. Diagnostic and Statistical 
Manual of Mental Disorders. 3rd ed revised APA Washington, 1988.

8 Meige H, Feindel E. Tics and their Treatment. Translated by SAK Wilson. New York: William Wood and Co, 1907.

9 Gilles de la Tourette G. La Maladie des Tics Convulsifs. La semaine medicale 1899;19:153-6.

10 Lees AJ, Robertson M, Trimble MR, Murray NMF. A clinical study of Gilles de la Tourette syndrome in the United Kingdom. J Neurol Neurosurg Psychiatry 1984;47:1-8.

11 Robertson M, Evans K, Robinson A, Trimble M, Lascelles P. Abnormalities of copper in Gilles de la Tourette syndrome. Biol Psychiatry 1987;22:968-78.

12 Robertson MM, Trimble MR, Lees AJ. Self injurious behaviour and the Gilles de la Tourette syndrome. A clinical study and review of the literature. Psychol Med (in press).

13 Robertson MM, Trimble MR. Some personality variables in functional neurological disorders. Behav Neurol 1988;1:23-8.

14 Crisp AH, Moldofsky H. A psychosomatic study of writer's cramp. Br J Psychiatry 1985;111:841-58.

15 Malmo RB, Shagasshc, Davis FH. Symptoms of specificity and bodily reactions during psychiatric interview. Psychosom Med 1950;12:363-76.

16 Frankel M, Cummings JL, Robertson MM, Trimble MR, Hill MA, Benson F. Obsessions and compulsions in Gilles de la Tourette syndrome. Neurology 1986;36:378-82.

17 Pauls DL, Tobin KE, Leckman JF, Zahner GEP, Cohen DG. Gilles de la Tourette syndrome and obsessive compulsive disorder. Arch Gen Psychiatry 1986;43:1180-2.

18 Comings DE, Comings BE, Devor EJ, Cloninger CR. Detection of major gene for Gilles de la Tourette syndrome. Am J Hum Genet 1984;36:586-600.

19 Pitman RK, Green RC, Jenike MA, Mesulam MM. Clinical comparison of Tourette's disorder and obsessive compulsive disorder. Am J Psychiatry 1987;144:1166-71.

20 Bliss J. Sensory experiences of Gilles de la Tourette syndrome. Arch Gen Psychiatry 1980;37:1343-7. 